\title{
Endoscopic endonasal control of the paraclival internal carotid artery by Fogarty balloon catheter inflation: an anatomical study
}

\author{
Andrea Ruggeri, MD, ${ }^{1}$ Joaquim Enseñat, $\mathrm{PhD},{ }^{2}$ Alberto Prats-Galino, $\mathrm{PhD},{ }^{3}$ \\ Antonio Lopez-Rueda, MD, ${ }^{4}$ Joan Berenguer, PhD, ${ }^{4}$ Martina Cappelletti, MD, \\ Matteo De Notaris, $\mathrm{PhD},{ }^{5}$ and Elena d'Avella, $\mathrm{MD}^{3,6}$
}

'Department of Neuroscience, Neurosurgery, University of Rome "Sapienza," Rome, Italy; 'Department of Neurosurgery,
Hospital Clinic, Faculty of Medicine, Universitat de Barcelona, Spain; ' 3 Laboratory of Surgical NeuroAnatomy (LSNA), Human
Anatomy and Embryology Unit, Faculty of Medicine, Universitat de Barcelona, Spain; “Department of Radiology, Hospital
Clinic, Faculty of Medicine, Universitat de Barcelona, Spain; ' ${ }^{5}$ Neurosurgical Department, "G. Rummo" Hospital of Benevento,
Benevento, Italy; and 'Department of Neuroscience, Neurosurgery, University of Padua, Italy

OBJECTIVE Neurosurgical management of many vascular and neoplastic lesions necessitates control of the internal carotid artery (ICA). The aim of this study was to investigate the feasibility of achieving control of the ICA through the endoscopic endonasal approach by temporary occlusion with a Fogarty balloon catheter.

\begin{abstract}
METHODS Ten endoscopic endonasal paraseptal approaches were performed on cadaveric specimens. A Fogarty balloon catheter was inserted through a sellar bony opening and pushed laterally and posteriorly extraarterially along the paraclival carotid artery. The balloon was then inflated, thus achieving temporary occlusion of the vessel. The position of the catheter was confirmed with CT scans, and occlusion of the ICA was demonstrated with angiography. The technique was performed in 2 surgical cases of pituitary macroadenoma with cavernous sinus invasion.
\end{abstract}

RESULTS Positioning the Fogarty balloon catheter at the level of the paraclival ICA was achieved in all cadaveric dissections and surgical cases through a minimally invasive, quick, and safe approach. Inflation of the Fogarty balloon caused interruption of blood flow in $100 \%$ of cases.

CONCLUSIONS Temporary occlusion of the paraclival ICA performed through the endoscopic endonasal route with the aid of a Fogarty balloon catheter may be another maneuver for dealing with intraoperative ICA control. Further clinical studies are required to prove the efficacy of this method.

https://thejns.org/doi/abs/10.3171/2016.1.JNS151962

KEY WORDS endoscopic endonasal; Fogarty balloon catheter; ICA; paraclival; proximal control; skull base

$\mathrm{T}$ HE endoscopic transsphenoidal approach has rapidly become the standard of care for pituitary tumors. ${ }^{1,5,22,27,28,34,43}$ Improvements in technologies and surgical techniques have led to the expansion of more advanced approaches, such as the fully endoscopic transnasal approach to the anterior cranial fossa, clivus, petrous bone, middle cranial fossa, and infratemporal fossa. ${ }^{8,10,13,24,25,38,42}$ With access to the parasellar area and the increased complexity of the addressed lesions, the danger of damaging major vascular structures raises the requirement for vascular control. , $^{14,18,23,25,27,42}$

One major drawback of this technique is the small surgical field and the narrow nasal corridor through which achieving vascular control and repair of main vascular injuries can be challenging. $4,14,17,18,23,27,30,41$

In 1993, Wascher et al. described a method of tempo- 
rary petrous internal carotid artery (ICA) occlusion using a Fogarty balloon embolectomy catheter, which was placed extraarterially within the carotid canal for cavernous sinus surgery. ${ }^{48}$ The aim of this anatomical study was to revisit this technique of ICA proximal control from the endoscopic endonasal route. The surgical technique, anatomical consideration, and possible clinical applications are discussed.

\section{Methods}

To perform this study, 10 fresh human cadaver heads were dissected at the Laboratory of Surgical Neuroanatomy in the Human Anatomy and Embryology Unit, Faculty of Medicine, Universitat de Barcelona, Spain. The surgical positioning of the head was simulated in the dissection laboratory; each head was slightly extended, turned $10^{\circ}$ toward the surgeon, and fixed in a rigid 3-pin MayfieldKees device. Endoscopic dissections were performed using a rigid endoscope that was $4 \mathrm{~mm}$ in diameter and $18 \mathrm{~cm}$ in length with $0^{\circ}$ and $30^{\circ}$ optics (Karl Storz). The endoscope was connected to a light source through a fiberoptic cable and to a camera (Endovision Telecam SL, Karl Storz) fitted with 3 charge-coupled device sensors. To obtain a suitable file of anatomical images, a digital videorecorder system was used.

\section{Results}

In our anatomical study, dissections were performed following the steps of the endoscopic endonasal paraseptal approach between the nasal septum and the middle turbinate. The posterior wall of the sphenoidal sinus was exposed. A bony opening was then created at the sellar floor, exposing the dura overlying the pituitary gland and thus safely gaining access to the dural layer. The bony fenestration was enlarged laterally and posteriorly as far as the paraclival ICA. A 40-cm 3-Fr Fogarty occlusion catheter (Edwards Lifesciences Corp.) was inserted at the bony opening and directed toward the paraclival carotid artery.

The Fogarty catheter was then pushed downward extraarterially (between the outer wall of the vessel and the bony wall of the carotid canal) until it naturally stopped (Fig. 1). The distal end of the catheter was connected to a 3-way stopcock that was attached to a syringe filled with normal saline solution. The balloon of the catheter was inflated with the saline solution and the stopcock was closed, providing a safe temporary occlusion of the paraclival ICA.

After dissection, CT scanning (Fig. 2) and angiography (Fig. 3) were performed in each cadaveric specimen to confirm the positioning of the Fogarty balloon catheter and ICA occlusion. We found a volume of $5 \mathrm{ml}$ of saline solution to be optimal for achieving interruption of blood flow across the paraclival ICA.

The described technique was performed during 2 surgical cases of pituitary macroadenoma with cavernous sinus invasion (Fig. 4A-D).

Please refer to Video 1, which briefly demonstrates the anatomical dissection and radiological studies that were

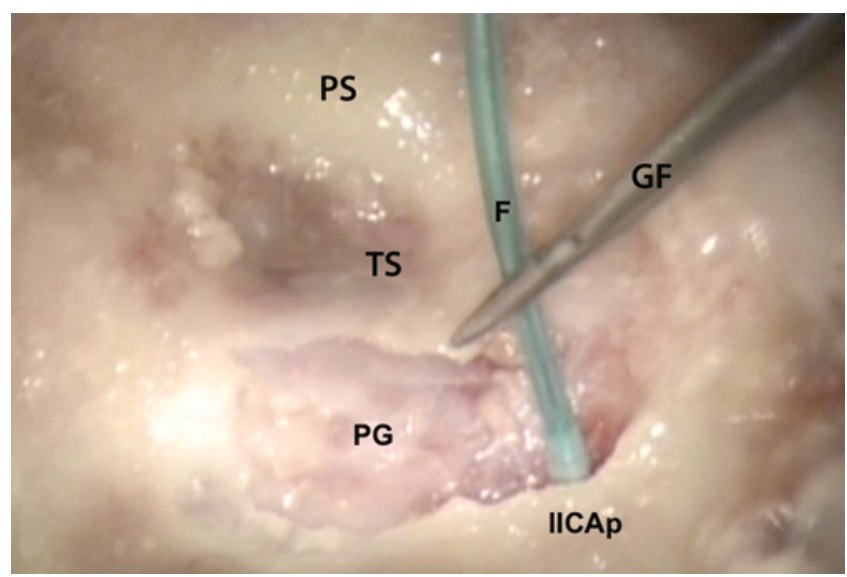

FIG. 1. Cadaveric dissection showing the exposure of the sellar dura and left paraclival ICA through an endoscopic endonasal paraseptal approach. A Fogarty balloon catheter is approximated to the bony opening and inserted extradurally and extraarterially along the paraclival ICA. The catheter is then pushed posteriorly and laterally toward the foramen lacerum until it naturally stops. $\mathrm{F}=$ Fogarty balloon catheter; $\mathrm{GF}=$ grasping forceps; IICAp = left paraclival ICA; PG = pituitary gland; PS = planum sphenoidale; $\mathrm{TS}=$ tuberculum sellae. Figure is available in color online only.

carried out during our study and one of the surgical cases on which the described technique was performed.

VIDEO 1. Demonstration of the anatomical dissection performed during our study. A Fogarty balloon catheter was positioned extraarterially at the paraclival ICA through the endoscopic endonasal paraseptal approach. CT scans show the position of the catheter, and angiography confirms the interruption of contrast flow at the paraclival ICA when the Fogarty balloon is inflated. This technique was performed on a surgical case of pituitary macroadenoma with cavernous sinus invasion. Copyright Elena d'Avella. Published with permission. Click here to view.

\section{Discussion}

Neurosurgical management of many vascular and neoplastic lesions necessitates control of the ICA, e.g., aneurysms of the paraclinoidal region, tumors invading the cavernous sinus, and skull base tumors. 2,26,33,45,46,48-50

Traditionally, exposing the cervical carotid vessels and placing temporary clips on the cervical ICA can obtain proximal control of the internal ICA..$^{9,11,31,39}$ However, neck dissection requires a separate incision and presents the distinct disadvantage of 2 separate operative fields should immediate control of bleeding be necessary, in addition to esthetic considerations., ${ }^{9,31}$ When proximal control of the arterial blood supply to the cavernous sinus region is needed, these disadvantages might be overcome by means of occlusion of the petrous ICA with aneurysm clips or

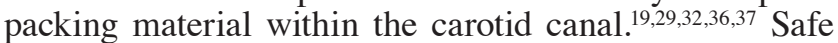
exposure of the petrous ICA requires thorough knowledge of the anatomical landmarks of the floor of the middle cranial fossa and is not without the potential for serious complications, such as hearing loss, facial palsy from traction injury to the greater superficial petrosal nerve, or laceration of the ICA when unroofing the carotid canal.19,29,37 After the initial exposure, the ICA must be separated from 

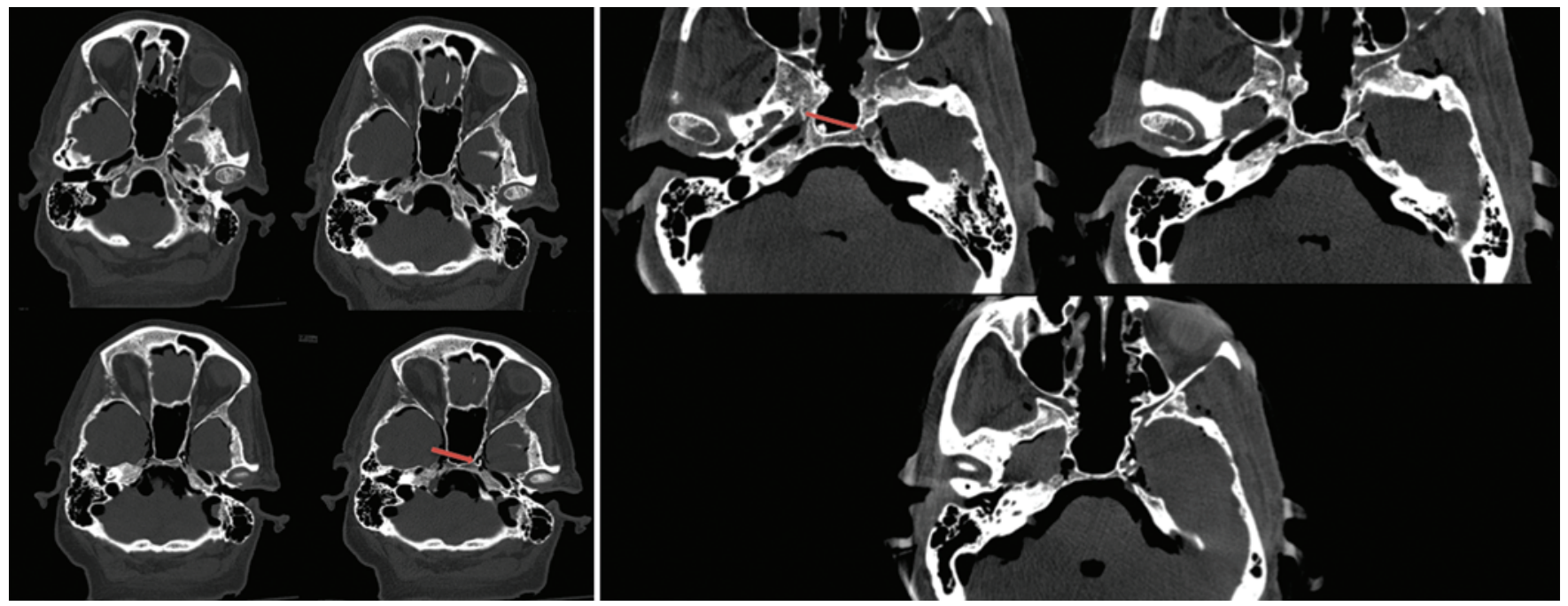

FIG. 2. CT scan (bone window, axial slices) showing the ICA course from the intrapetrous to the paraclival segment with a clockwise caudocranial progression. At the level of the left paraclival ICA, the metallic core of the distal end of the Fogarty catheter (left) and the balloon after inflation (right) are visible (red arrows). Figure is available in color online only.

its sheath of periosteum, venous channels, and sympathetic nerve fibers in order to allow placement of temporary aneurysm clips in preparation for grafting or temporary

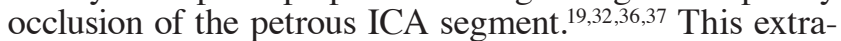
dural approach has been modified by performing a transdural exposure of the petrous ICA and occluding the ICA temporarily with a Fogarty balloon catheter that is placed extraarterially within the proximal carotid canal. This modification is faster and technically simpler than the complete circumferential dissection of the petrous ICA that is required when the occlusion is to be provided by the application of temporary aneurysm clips. ${ }^{47}$

Endovascular balloon inflation has also been used to achieve both proximal and distal control of the ICA during aneurysm surgery and proven to be extremely helpful in interrupting local blood flow. ${ }^{12,20,35,40,44}$ The advantages of this technique include greater exposure of the aneurysm for permanent clipping due to the elimination of the need for temporary clips, the improved accuracy of clip placement, and the reduction of the risk of intramural aneurysm thrombus dislodgment due to multiple temporary clipping. ${ }^{12,40,44}$ However, there are several disadvantages to the routine use of endovascular intraoperative techniques. A dedicated interventional radiologist must stay in the operating room during surgery. Some degree of radiation exposure for the patient and the operating room personnel is unavoidable during an intraoperative angiography procedure. The additional time required for the endovascular setup and intraoperative angiography is usually around 1 hour. The addition of endovascular adjuncts to aneurysm
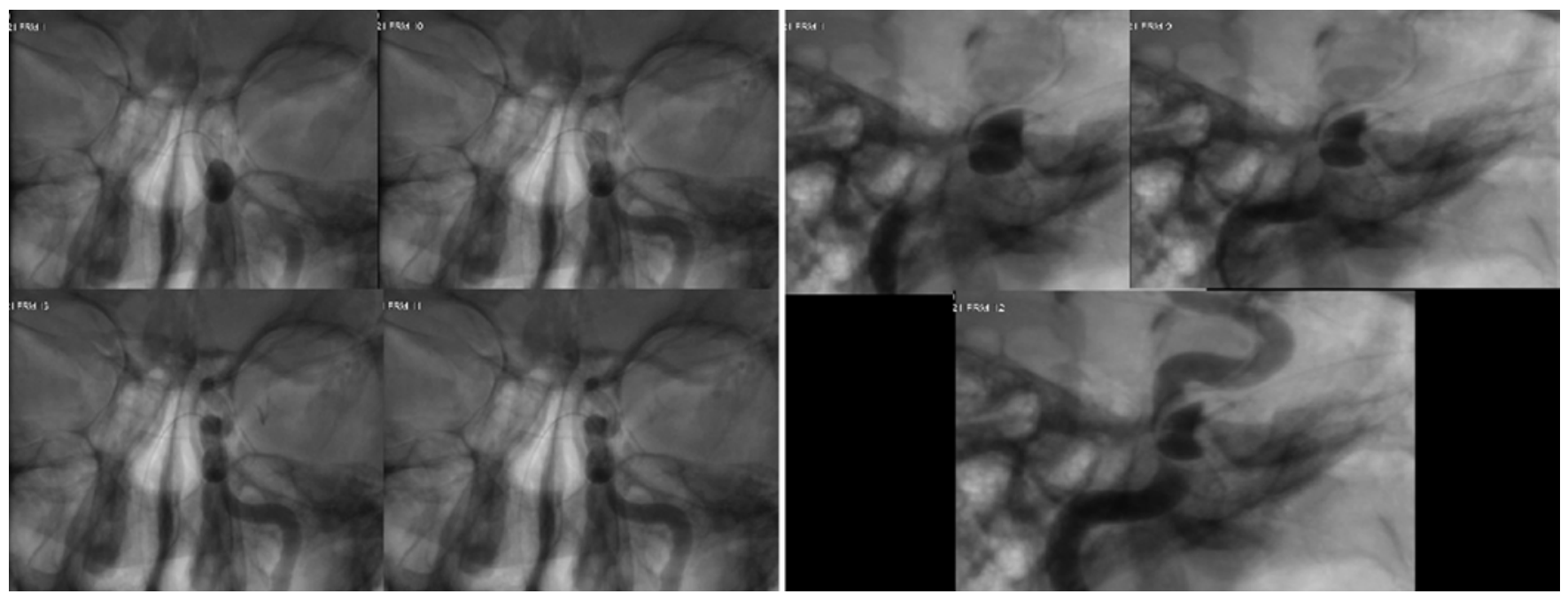

FIG. 3. Anterior (right) and lateral (left) cerebral angiograms of the left ICA. Clockwise, the images show the interruption of contrast flow when the Fogarty catheter balloon is inflated at the level of the paraclival ICA, and the progressive passage of contrast as the balloon is deflated. 


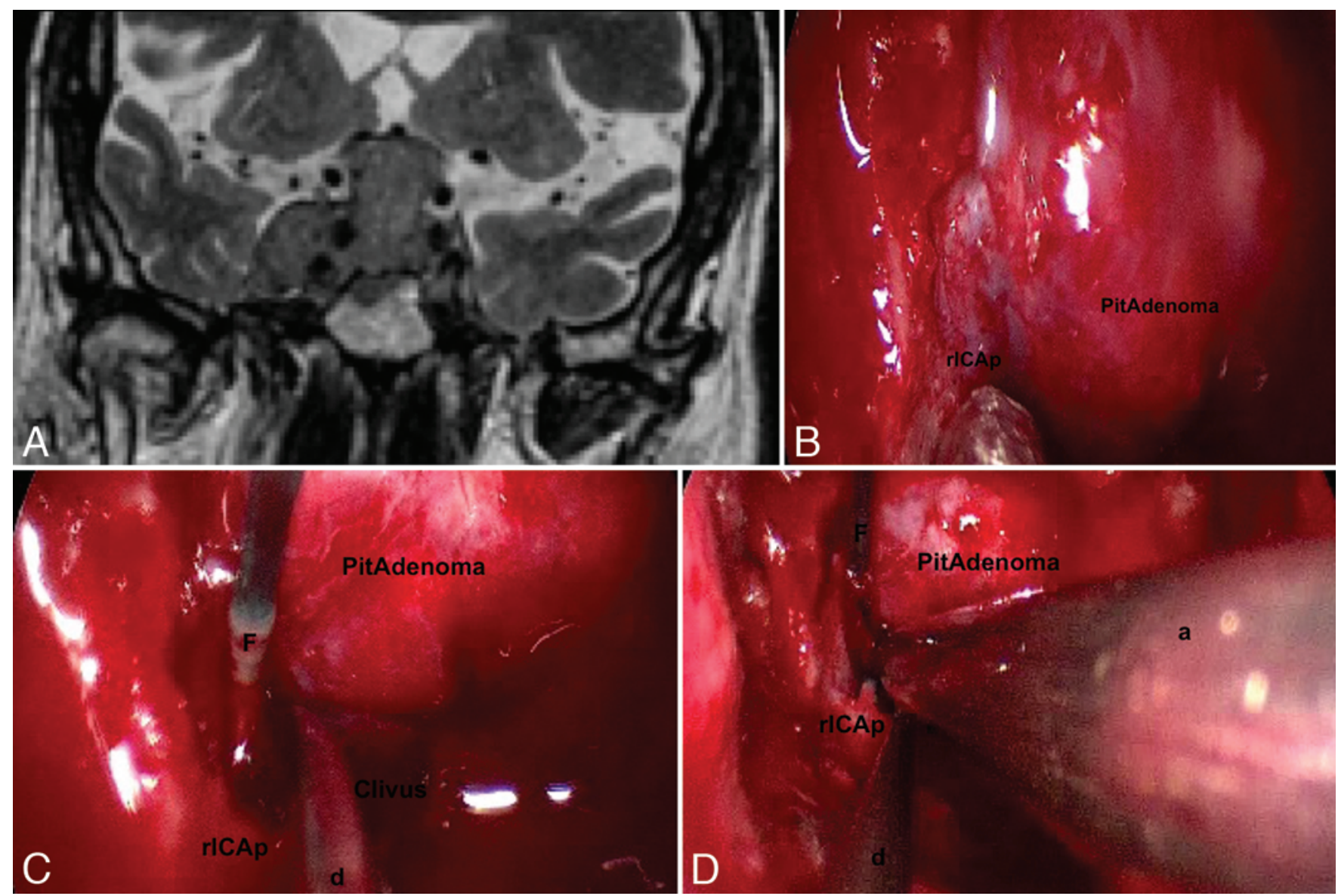

FIG. 4. A: Magnetic resonance image showing a right macroadenoma with cavernous sinus invasion. The patient underwent endoscopic endonasal surgery. B: The paraseptal approach was performed. The pituitary adenoma and right paraclival ICA were exposed. C: A Fogarty balloon catheter was inserted extraarterially and extradurally along the paraclival ICA until it naturally stopped. D: The catheter was left in situ to be inflated in case of intraoperative ICA rupture. $a=$ aspirator; $d=$ dissector; $F=F o g-$ arty balloon catheter; PitAdenoma = pituitary adenoma; rICAp = right paraclival ICA. Figure is available in color online only.

surgery may be associated with potential embolic complications. ${ }^{12,20,35}$

In this anatomical study, we investigated the feasibility of achieving control of the ICA through the endoscopic endonasal approach by temporary occlusion with a Fogarty balloon catheter. In our opinion, using a Fogarty catheter rather than temporary aneurysm clips is well suited to endoscopic endonasal surgery. The complete circumferential dissection of the ICA that is required when the occlusion is to be provided by the application of temporary aneurysm clips may be complicated by the small and deep corridor provided by the endonasal route. Furthermore, the use of a Fogarty catheter instead of vascular clips increases the available space to perform surgical maneuvers around the ICA.

\section{Anatomical and Technical Considerations}

In this anatomical study, temporary occlusion of the ICA with a Fogarty balloon catheter was achieved in all cases through a paraseptal approach, which can be considered a fast, safe, and minimally invasive procedure. .,34 $^{2}$
Exposure of the ICA bilaterally in the sellar region can be achieved with this approach with no need for the removal of the middle turbinate. ${ }^{1,5,22,27,43}$ The paraclival segment of the ICA is easily recognized and accessed., ${ }^{1,5,22,34}$ Occlusion of the ICA is gained extradurally, thus eliminating the risk of cerebrospinal fluid leakage, which is often associated with the majority of endoscopic endonasal procedures. If the interruption of blood flow across the ICA has to be obtained by compression, the Fogarty balloon catheter has to be inflated where the vessels are surrounded by rigid structures. Otherwise, the ICA will be displaced and not occluded, with the risk of damaging other anatomical structures. Theoretically, the petrous ICA at the foramen lacerum fulfills this anatomical and functional criterion. We started anatomical dissections with the aim of inflating the Fogarty catheter at this level, thus compressing the artery against the bone of the posterior wall of the sphenoidal sinus ventrally, the petroclival junction medially, the dura of the temporal lobe laterally, and the fibrous lower portion of the foramen lacerum dorsally. During our study, however, we found that the catheter naturally stops before reaching the petrous ICA along the course 
of the paraclival ICA, where it hits the inferior petrosal ligament or any other bony prominence. The encasement of the paraclival ICA was rigid enough, thus allowing for it to be compressed and occluded by the Fogarty balloon without needing to reach the foramen lacerum. The important neurovascular structures at this level are the posterior apex of the cavernous sinus and the sympathetic fibers traveling from the surface of the carotid to the abducens nerve before ultimately being distributed to the first trigeminal division. ${ }^{3,7,41}$ Since compression is temporal and causes minimal displacement of the ICA, this anatomical relationship should not represent a contraindication to the technique.

\section{Possible Clinical Applications}

Temporary occlusion with a Fogarty catheter balloon of the paraclival ICA through the endoscopic endonasal paraseptal approach can be used, should intraoperative rupture of the vessel occur. Operating around the ICA creates the possibility of its rupture., $4,6,15,16,21,41,46$ The endoscopic endonasal approach is minimally invasive and access to the ICA is minimal. . $^{15,16,46}$ This is especially true in the case of endoscopic endonasal skull base surgery due to the long narrow surgical corridor and the difficulty of maintaining endoscopic vision of the injury within a visual field that becomes quickly obscured., ${ }^{4,6,15-17,21,30,46}$ ICA injury during endoscopic pituitary surgery is an infrequent event, with an incidence of $0.5 \%$ to $1.1 \%$. However, more extended endoscopic resections have a higher incidence of ICA rupture at $4 \%$ to $9 \% .^{4,6,17,30,41}$ We reported 2 surgical cases of pituitary macroadenoma invading the cavernous sinus that we considered at high risk for ICA injury. The Fogarty balloon catheter was positioned at the paraclival ICA before tumor removal was started. In the case of rupture of the artery, this would have given us the chance to temporally control the surgical field, avoiding indiscriminate nasal packing and vascular occlusion and perhaps reducing complications and saving the patient's life. Once the surgical field is controlled, hemostatic techniques can be implemented under endoscopic visualization or, if necessary, by resorting to other surgical or endovascular maneuvers.

The technique of ICA temporary occlusion may be a useful option during the removal of highly vascularized tumors of the suprasellar region, cavernous sinus, and anterior cranial fossa. By occluding the artery, blood flow to the tumor can be reduced, thus facilitating its debulking.

The application of endonasal surgery remains controversial for vascular lesions. ${ }^{14,18,23,27}$ The technique we described in this study could simplify achieving proximal control of the ICA in the setting of endoscopic endonasal surgery for a vascular lesion in the anterior circulation. Given the limited visualization area, circumferential dissection of the ICA to allow placement of temporary clips may be complicated, especially in the setting of intraoperative rupture. Positioning temporary clips further reduces the surgical space, complicating dissection of the aneurysm and clipping of the neck with preservation of the perforators. Control of the proximal anterior communicating arteries, which are hidden above the optic nerves and chiasm, can be risky. A potential bilateral occlusion of the paraclival ICA by compression with a Fogarty balloon may allow for the control of contralateral blood flow across an anterior communicating artery aneurysm.

Besides the application of the temporary occlusion of the paraclival ICA with a Fogarty balloon catheter to pure skull base endoscopic endonasal surgery, this technique might be considered for cases that use endoscope-assisted transcranial microsurgical approaches. When vascular control of the ICA has to be planned before starting transcranial surgery, e.g., for paraclinoidal aneurysm surgery, an endoscopic endonasal paraseptal approach can be performed and the Fogarty catheter left in situ as an alternative to exposing the cervical carotid vessels or performing endovascular techniques. The balloon may then be inflated or not, depending on the surgical needs.

\section{Tips and Complications}

In our experience, Fogarty balloon placement into the paraclival ICA canal results in a fast and easy procedure. The average time for balloon positioning could be estimated to be between 3 and 10 minutes. A 4-hand technique is required, with 1 surgeon holding the endoscope and the instrument, and the other inserting the catheter from the contralateral nostril and keeping the surgical field clean with aspiration. Once the Fogarty catheter appears in the sphenoid cavity, it must be directed anteroposteriorly, with its distal end leaning on the planum sphenoidale. The catheter is brought closer to the paraclival ICA and pushed extraarterially along the artery with the use of grasping forceps, taking care not to damage the balloon by grasping the catheter too close to its proximal end. Bone removal at the sellar floor is minimal, just as much as is required to access the dural plane. Exposing the dura of the sella and then extending the bone removal laterally toward the paraclival ICA is probably safer than a straight exposure of the artery by drilling the paraclival bone protuberance. Exposure of the paraclival ICA is reduced to its identification, with no need for wider visualization of the artery. The Fogarty balloon is inserted extraarterially along the paraclival ICA with a direction parallel to the course of the artery. No specific angulation of the catheter is required since it will naturally advance along the ICA, as any other direction is obstructed by the rigid bony and dural structures that encase the carotid at this level. Once the surgeon feels any resistance when inserting the Fogarty catheter extraarterially along the paraclival ICA, the maneuver should stop. Any attempt to further push the Fogarty catheter could cause rupture of the balloon against bony edges. Insertion of the balloon for a few millimeters inside the paraclival ICA canal is enough to obtain the vessel's compression and occlusion when the balloon is inflated (Fig. 5).

The potential risks and complications of temporary occlusion of the paraclival ICA are stroke and thromboembolism. Neuromonitoring of brain activity, e.g., with electroencephalography or evoked potentials, is recommended during surgery. Another possible complication could be direct damage to the carotid artery by positioning and inflating the Fogarty balloon. In our study, we did not experience this. Postoperative CT or MR angiography could allow for the assessment of ICA patency at the same 

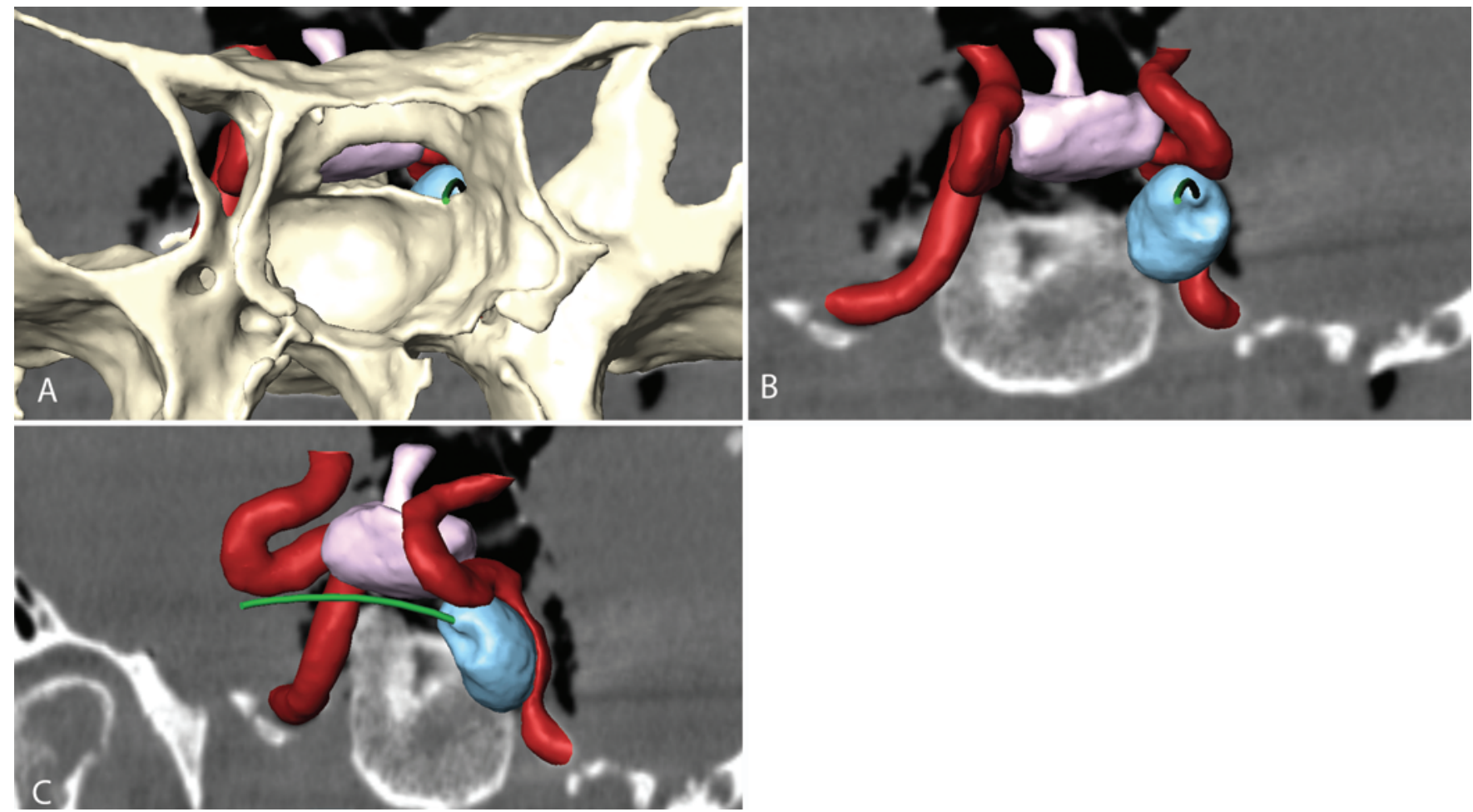

FIG. 5. A 3D reconstruction of the endoscopic endonasal paraseptal approach was obtained with Amira (Amira Visage Imaging Inc.), a specific software program for the visualization and manipulation of biomedical data. A: Bone removal at the sellar floor and the paraclival ICA protuberance with visualization of the pituitary gland (purple), left paraclival ICA (red), and Fogarty balloon (blue) catheter (green). B: Localization of the Fogarty balloon catheter compressing the left ICA. C: The left ICA is compressed and occluded by the Fogarty balloon. Figure is available in color online only.

time as the extension of lesion removal. The presence of the Fogarty catheter inside the small surgical area provided by the endoscopic endonasal approach to the cavernous sinus region could represent an impediment during tumor removal. However, in our experience, we were able to remove the cavernous portion of the pituitary adenomas. Because of its small diameter, the Fogarty catheter does not obstruct the entrance of any other surgical instruments. It is flexible and it can be sutured outside the nasal cavity; thus, the Fogarty balloon would not accidentally exit the paraclival ICA canal during surgical maneuvers.

\section{Conclusions}

This anatomical study shows that temporary occlusion of the paraclival ICA with a Fogarty balloon catheter through the endoscopic endonasal route might be another maneuver that is useful for obtaining intraoperative control of the vessel, which is an alternative to complex microsurgical approaches that expose the petrous ICA, temporary clips in the surgical field, or endovascular techniques. It is a fast, safe, minimally invasive, and potentially temporary bilateral technique. This study also demonstrates another means by which the endonasal endoscopic approach can enhance the neurosurgical armamentarium. Further clinical studies are needed to prove the efficacy of this method.

\section{Acknowledgments}

This work was partly supported by grants from the
Marató TV3 Project (no. 411/U/2011; Title: Quantitative analysis and computer aided simulation of minimally invasive approaches for intracranial vascular lesions).

\section{References}

1. Alahmadi H, Dehdashti AR, Gentili F: Endoscopic endonasal surgery in recurrent and residual pituitary adenomas after microscopic resection. World Neurosurg 77:540-547, 2012

2. Almefty R, Dunn IF, Pravdenkova S, Abolfotoh M, AlMefty O: True petroclival meningiomas: results of surgical management. J Neurosurg 120:40-51, 2014

3. Barges-Coll J, Fernandez-Miranda JC, Prevedello DM, Gardner P, Morera V, Madhok R, et al: Avoiding injury to the abducens nerve during expanded endonasal endoscopic surgery: anatomic and clinical case studies. Neurosurgery 67:144-154, 2010

4. Berker M, Aghayev K, Saatci I, Palaoğlu S, Onerci M: Overview of vascular complications of pituitary surgery with special emphasis on unexpected abnormality. Pituitary 13:160-167, 2010

5. Cappabianca P, Cavallo LM, Solari D, Stagno V, Esposito F, de Angelis M: Endoscopic endonasal surgery for pituitary adenomas. World Neurosurg 82 (6 Suppl):S3-S11, 2014

6. Cavallo LM, Briganti F, Cappabianca P, Maiuri F, Valente $\mathrm{V}$, Tortora F, et al: Hemorrhagic vascular complications of endoscopic transsphenoidal surgery. Minim Invasive Neurosurg 47:145-150, 2004

7. de Lara D, Ditzel Filho LF, Prevedello DM, Carrau RL, Kasemsiri P, Otto BA, et al: Endonasal endoscopic 
approaches to the paramedian skull base. World Neurosurg 82 (6 Suppl):S121-S129, 2014

8. Dehdashti AR, Ganna A, Witterick I, Gentili F: Expanded endoscopic endonasal approach for anterior cranial base and suprasellar lesions: indications and limitations. Neurosurgery 64:677-689, 2009

9. De Jesús O, Sekhar LN, Riedel CJ: Clinoid and paraclinoid aneurysms: surgical anatomy, operative techniques, and outcome. Surg Neurol 51:477-488, 1999

10. Di Maio S, Cavallo LM, Esposito F, Stagno V, Corriero OV, Cappabianca P: Extended endoscopic endonasal approach for selected pituitary adenomas: early experience. J Neurosurg 114:345-353, 2011

11. Dolenc VV: Anatomy and Surgery of the Cavernous Sinus. New York: Springer, 1989

12. Elhammady MS, Nakaji P, Farhat H, Morcos JJ, Aziz-Sultan MA: Balloon-assisted clipping of a large paraclinoidal aneurysm: a salvage procedure. Neurosurgery 65:E1210E1211, 2009

13. Frank G, Sciarretta V, Calbucci F, Farneti G, Mazzatenta D, Pasquini E: The endoscopic transnasal transsphenoidal approach for the treatment of cranial base chordomas and chondrosarcomas. Neurosurgery 59 (1 Suppl 1):ONS50ONS57, 2006

14. Froelich S, Cebula H, Debry C, Boyer P: Anterior communicating artery aneurysm clipped via an endoscopic endonasal approach: technical note. Neurosurgery 68 (2 Suppl Operative):310-316, 2011

15. Fukushima T, Maroon JC: Repair of carotid artery perforations during transsphenoidal surgery. Surg Neurol 50:174-177, 1998

16. Gadhinglajkar SV, Sreedhar R, Bhattacharya RN: Carotid artery injury during transsphenoidal resection of pituitary tumor: anesthesia perspective. J Neurosurg Anesthesiol 15:323-326, 2003

17. Gardner PA, Tormenti MJ, Pant H, Fernandez-Miranda JC, Snyderman CH, Horowitz MB: Carotid artery injury during endoscopic endonasal skull base surgery: incidence and outcomes. Neurosurgery 73 (2 Suppl Operative):ons261ons270, 2013

18. Germanwala AV, Zanation M: Endoscopic endonasal approach for clipping of ruptured and unruptured paraclinoid cerebral aneurysms: case report. Neurosurgery 68 (1 Suppl Operative): $234-240,2011$

19. Glassock ME III, Smith PG, Bond AG, Whitaker SR, Bartels LJ: Management of aneurysms of the petrous portion of the internal carotid artery by resection and primary anastomosis. Laryngoscope 93:1445-1453, 1983

20. Hoh BL, Carter BS, Budzik RF, Putman CM, Ogilvy CS: Results after surgical and endovascular treatment of paraclinoid aneurysms by a combined neurovascular team. Neurosurgery 48:78-90, 2001

21. Inamasu J, Guiot BH: Iatrogenic carotid artery injury in neurosurgery. Neurosurg Rev 28:239-248, 2005

22. Karppinen A, Kivipelto L, Vehkavaara S, Ritvonen E, Tikkanen E, Kivisaari R, et al: Transition from microscopic to endoscopic transsphenoidal surgery for nonfunctional pituitary adenomas. World Neurosurg 84:48-57, 2015

23. Kassam AB, Gardner PA, Mintz A, Snyderman CH, Carrau RL, Horowitz M: Endoscopic endonasal clipping of an unsecured superior hypophyseal artery aneurysm. Technical note. J Neurosurg 107:1047-1052, 2007

24. Kassam AB, Gardner P, Snyderman C, Mintz A, Carrau R: Expanded endonasal approach: fully endoscopic, completely transnasal approach to the middle third of the clivus, petrous bone, middle cranial fossa, and infratemporal fossa. Neurosurg Focus 19(1):E6, 2005

25. Kassam AB, Prevedello DM, Carrau RL, Snyderman CH,
Gardner P, Osawa S, et al: The front door to Meckel's cave: an anteromedial corridor via expanded endoscopic endonasal approach- technical considerations and clinical series. Neurosurgery 64 (3 Suppl):ons71-ons83, 2009

26. Khan N, Yoshimura S, Roth P, Cesnulis E, KoenueLeblebicioglu D, Curcic M, et al: Conventional microsurgical treatment of paraclinoid aneurysms: state of the art with the use of the selective extradural anterior clinoidectomy SEAC. Acta Neurochir Suppl 94:23-29, 2005

27. Kitano M, Taneda M: Extended transsphenoidal approach to anterior communicating artery aneurysm: aneurysm incidentally identified during macroadenoma resection: technical case report. Neurosurgery 61 (5 Suppl 2):E299E300, 2007

28. Koutourousiou M, Gardner PA, Fernandez-Miranda JC, Paluzzi A, Wang EW, Snyderman CH: Endoscopic endonasal surgery for giant pituitary adenomas: advantages and limitations. J Neurosurg 118:621-631, 2013

29. Lang J: [Skull Base and Related Structures: Atlas of Clinical Anatomy.] Stuttgart: Schattauer, 1995 (Ger)

30. Laws ER Jr: Vascular complications of transsphenoidal surgery. Pituitary 2:163-170, 1999

31. Little JR, Rosenfeld JV, Awad IA: Internal carotid artery occlusion for cavernous segment aneurysm. Neurosurgery 25:398-404, 1989

32. Liu JK, Fukushima T, Sameshima T, Al-Mefty O, Couldwell WT: Increasing exposure of the petrous internal carotid artery for revascularization using the transzygomatic extended middle fossa approach: a cadaveric morphometric study. Neurosurgery 59 (4 Suppl 2):ONS309-ONS319, 2006

33. Maruyama K, Shin M, Kurita H, Kawahara N, Morita A, Kirino T: Proposed treatment strategy for cavernous sinus meningiomas: a prospective study. Neurosurgery 55:10681075,2004

34. Messerer M, Dubourg J: Endoscopic pituitary surgery. J Neurosurg 121:1533, 2014

35. Ng PY, Huddle D, Gunel M, Awad IA: Intraoperative endovascular treatment as an adjunct to microsurgical clipping of paraclinoid aneurysms. J Neurosurg 93:554-560, 2000

36. Osawa S, Rhoton AL Jr, Tanriover N, Shimizu S, Fujii K: Microsurgical anatomy and surgical exposure of the petrous segment of the internal carotid artery. Neurosurgery 63 (4 Suppl 2):210-239, 2008

37. Paullus WS, Pait TG, Rhoton AI Jr: Microsurgical exposure of the petrous portion of the carotid artery. J Neurosurg 47:713-726, 1977

38. Paluzzi A, Gardner P, Fernandez-Miranda JC, Snyderman C: The expanding role of endoscopic skull base surgery. $\mathbf{B r} \mathbf{J}$ Neurosurg 26:649-661, 2012

39. Sekhar LN, Schramm VL Jr, Jones NF, Yonas H, Horton $\mathrm{J}$, Latchaw RE, et al: Operative exposure and management of the petrous and upper cervical internal carotid artery. Neurosurgery 19:967-982, 1986

40. Skrap M, Petralia B, Toniato G: Temporary balloon occlusion during the surgical treatment of giant paraclinoid and vertebrobasilar aneurysms. Acta Neurochir (Wien) 152:435-442, 2010

41. Solares CA, Ong YK, Carrau RL, Fernandez-Miranda J, Prevedello DM, Snyderman CH, et al: Prevention and management of vascular injuries in endoscopic surgery of the sinonasal tract and skull base. Otolaryngol Clin North Am 43:817-825, 2010

42. Solari D, Chiaramonte C, Di Somma A, Dell'Aversana Orabona G, de Notaris M, Angileri FF, et al: Endoscopic anatomy of the skull base explored through the nose. World Neurosurg 82 (6 Suppl):S164-S170, 2014 
43. Stippler M, Gardner PA, Snyderman CH, Carrau RL, Prevedello DM, Kassam AB: Endoscopic endonasal approach for clival chordomas. Neurosurgery 64:268-278, 2009

44. Tao YX, Qu QY, Wang ZL, Zhang QH: Endoscopic transsphenoidal approach to pituitary adenomas invading the cavernous sinus. Chin Med J (Engl) 123:3519-3523, 2010

45. Thorell W, Rasmussen P, Perl J, Masaryk T, Mayberg M: Balloon-assisted microvascular clipping of paraclinoid aneurysms. Technical note. J Neurosurg 100:713-716, 2004

46. Valentine R, Wormald PJ: Controlling the surgical field during a large endoscopic vascular injury. Laryngoscope 121:562-566, 2011

47. Wanibuchi M, Akiyama Y, Mikami T, Iihoshi S, Miyata $\mathrm{K}$, Horita Y, et al: Radical removal of recurrent malignant meningeal tumors of the cavernous sinus in combination with high-flow bypass. World Neurosurg 83:424-430, 2015

48. Wascher TM, Spetzler RF, Zabramski JM: Improved transdural exposure and temporary occlusion of the petrous internal carotid artery for cavernous sinus surgery. Technical note. J Neurosurg 78:834-837, 1993

49. Xu BN, Sun ZH, Romani R, Jiang JL, Wu C, Zhou DB, et al: Microsurgical management of large and giant paraclinoid aneurysms. World Neurosurg 73:137-146, e17, e19, 2010

50. Zipfel GJ, Day AL: Surgical treatment of clinoid and ophthalmic segment internal carotid artery aneurysms, in Le Roux PD, Winn HR, Newell DW (eds): Management of Cerebral Aneurysms. Philadelphia: Saunders, 2004, pp 731-744

\section{Disclosures}

The authors report no conflict of interest concerning the materials or methods used in this study or the findings specified in this paper.

\section{Author Contributions}

Conception and design: d'Avella, Ruggeri. Acquisition of data: d'Avella, Enseñat, Lopez-Rueda. Analysis and interpretation of data: Berenguer. Drafting the article: Cappelletti. Critically revising the article: Ruggeri, Enseñat, Prats-Galino, Berenguer, de Notaris. Administrative/technical/material support: Lopez-Rueda. Study supervision: Prats-Galino.

\section{Supplemental Information Videos}

Video 1. https://vimeo.com/154999003.

\section{Correspondence}

Elena d'Avella, Laboratory of Surgical NeuroAnatomy, Human Anatomy and Embryology Unit, Faculty of Medicine, Universitat de Barcelona, C/ Casanova 143, Barcelona 08036, Spain. email: elenadavella@gmail.com. 